\title{
Responses to crizotinib and chemotherapy in patients with lung adenocarcinoma harboring a concomitant EGFR mutation and $A L K$ gene rearrangement: A case report and review of the literature
}

\author{
YUPING LI $^{1 *}$, SHANSHAN SU ${ }^{1 *}$, GUOPING CAI ${ }^{2}$, QUAN LIN ${ }^{1}$, YING ZHOU ${ }^{1}$, \\ JINSHENG OUYANG ${ }^{1}$, BICHENG CHEN $^{3}$, JUNRU YE ${ }^{1}$, XIULING WU $^{4}$ and CHENGSHUI CHEN ${ }^{1}$

\begin{abstract}
${ }^{1}$ Department of Pulmonary Medicine, The First Affiliated Hospital of Wenzhou Medical University, Wenzhou, Zhejiang 325015, P.R. China; ${ }^{2}$ Department of Pathology, Yale University School of Medicine, New Haven, CT 06520,

USA; ${ }^{3}$ Surgical Laboratory Center; ${ }^{4}$ Department of Pathology, The First Affiliated Hospital of Wenzhou Medical University, Wenzhou, Zhejiang 325015, P.R. China
\end{abstract}

Received September 23, 2016; Accepted April 4, 2017

DOI: $10.3892 / \mathrm{mco} .2017 .1306$

\begin{abstract}
Previous studies have indicated that, in lung cancers, the gene rearrangement of $A L K$ is mutually exclusive with mutations in the epidermal growth factor receptor $(E G F R)$ gene. However, the coexistence of EML4-ALK fusions and $E G F R$ mutations (double positive) has been occasionally reported, with frequencies ranging from 0-8\%. Currently, no consensus standard therapy exists for tumors with double positive mutations. In the present case report, the case is described of a 53-year-old woman with stage IV lung adenocarcinoma, harboring a concomitant $E G F R$ mutation and $A L K$ gene rearrangement, who was refractory to gefitinib administration but demonstrated a good response to crizotinib and pemetrexed chemotherapy. A review of the literature revealed a total of 65 cases, including our case, harboring double positive mutations, and of these cases, 39 (60.0\%) patients had received an EGFR tyrosine kinase inhibitor (EHGR-TKI), and 15 (23\%) patients had received crizotinib treatment, the majority of whom had crizotinib selected for them as a second-line or third-line therapy. The disease control rate (DCR) of EGFR-TKI was $72.2 \%$, with the progression-free survival
\end{abstract}

Correspondence to: $\operatorname{Dr}$ Chengshui Chen, Department of Pulmonary Medicine, The First Affiliated Hospital of Wenzhou Medical University, South Baixiang, Ouhai, Wenzhou, Zhejiang 325015, P.R. China

E-mail: wzchencs@163.com

*Contributed equally

Key words: epidermal growth factor receptor, anaplastic lymphoma kinase, lung neoplasms, epidermal growth factor receptor tyrosine kinase inhibitor
(PFS) being 11.9 months, whereas the DCR of crizotinib was 93.3\%, with the PFS being 10 months.

\section{Introduction}

Previous studies have indicated that, in lung cancers, the gene rearrangement of $A L K$ is mutually exclusive with mutations in the epidermal growth factor receptor $(E G F R)$ gene (1). However, the coexistence of EML4-ALK fusions and EGFR mutations (double positive) has been occasionally reported in a small proportion of patients (2-27). Currently, there is no consensus opinion regarding the treatment of these patients with double positive molecular alterations. The effectiveness of precision therapy also remains unknown. The present study reports the case of a 53-year-old woman with stage IV lung adenocarcinoma, who was treated with first-line chemotherapy with a regime of cisplatin $\left(75 \mathrm{mg} / \mathrm{m}^{2}\right)$ and pemetrexed (PEM) $\left(500 \mathrm{mg} / \mathrm{m}^{2}\right)$ every three weeks up to four cycles, followed by PEM maintenance therapy. As the disease progressed, the patient underwent a repeat biopsy, which revealed mutation of the $E G F R$ as well as an $A L K$ gene rearrangement. Gefitinib administration proved to be ineffective, although crizotinib revealed a partial response (PR). In addition, all the cases reported in the English literature of concomitant EGFR mutations with $A L K$ gene rearrangement were reviewed.

\section{Case report}

A 53-year-old female non-smoker was admitted to our hospital (The First Affiliated Hospital of Wenzhou Medical University, Wenzhou, China) for right chest discomfort in September 2013. A chest computed tomography (CT) scan revealed a $4.0 \times 3.5 \mathrm{~cm}$ mass in the right upper lobe, with moderate pleural effusion (Fig. 1). The patient underwent thoracentesis. The pleural effusion specimen revealed the presence of malignant cells, which were positive for thyroid transcription factor-1 and negative for p63, consistent with 


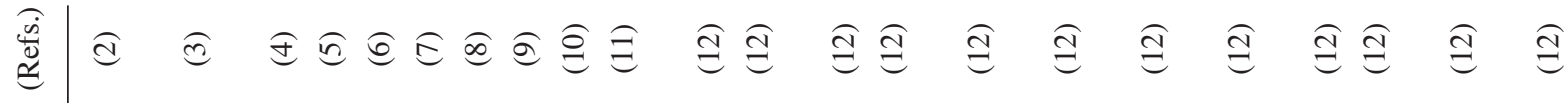
离

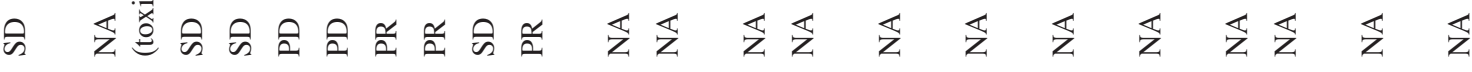
势

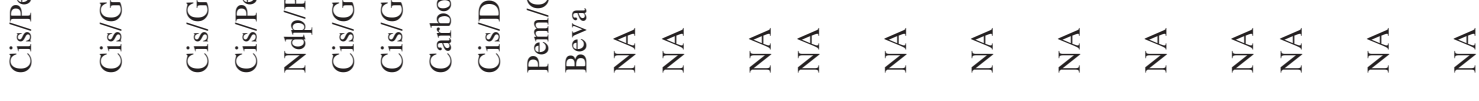

崫全+

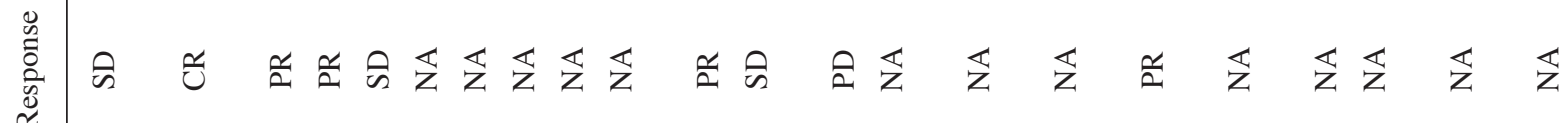

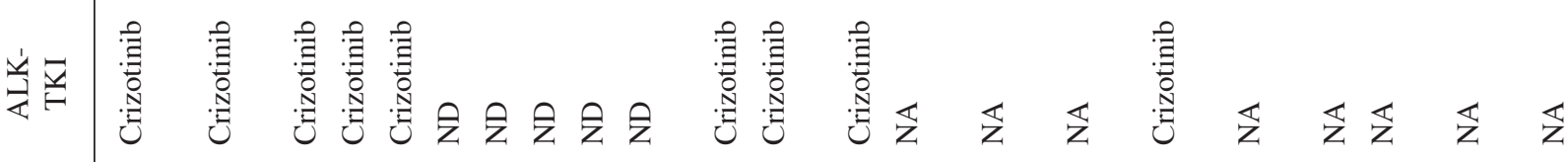

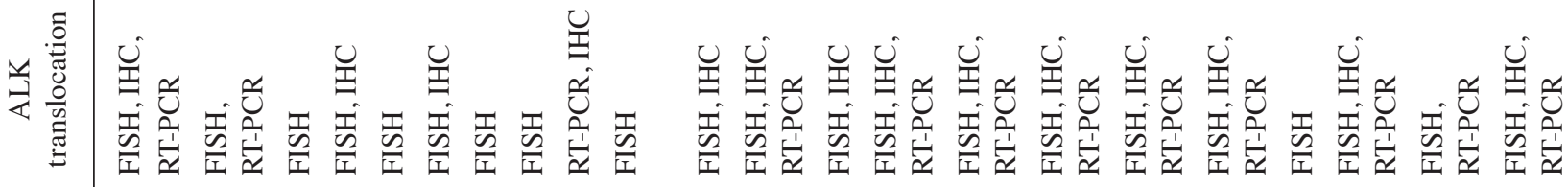

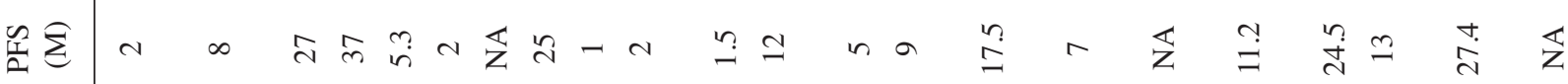

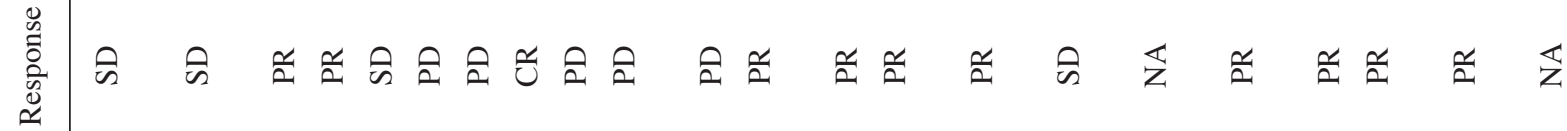

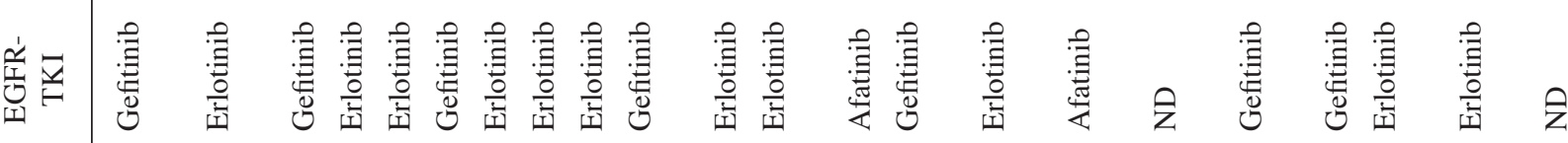

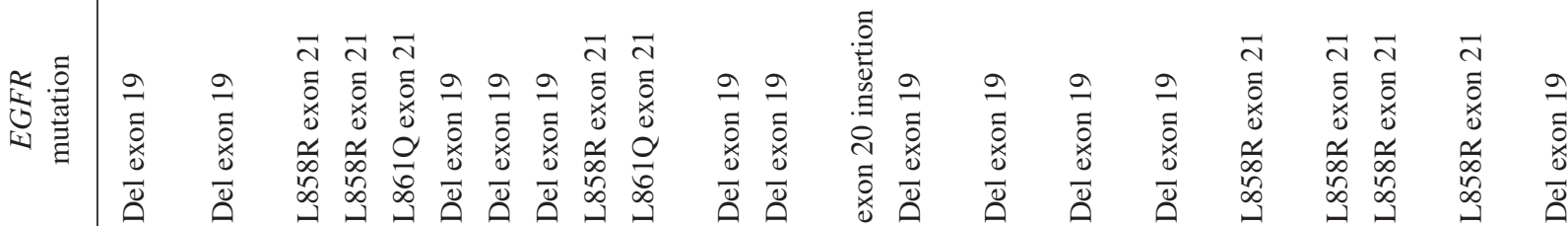

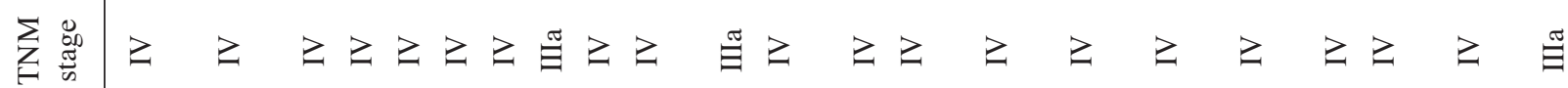

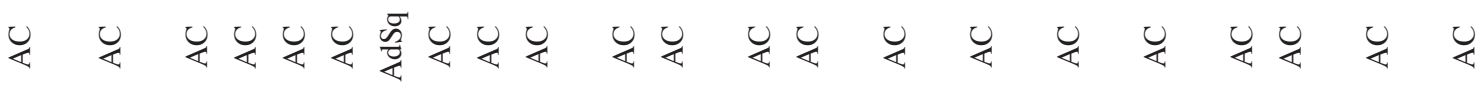

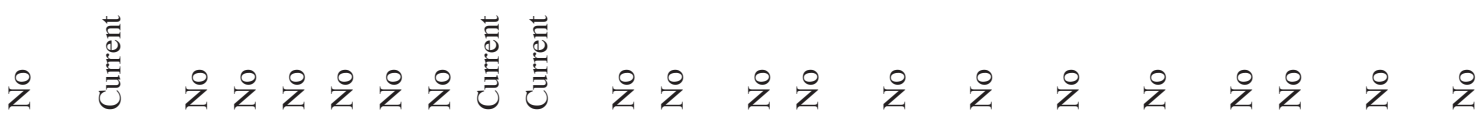

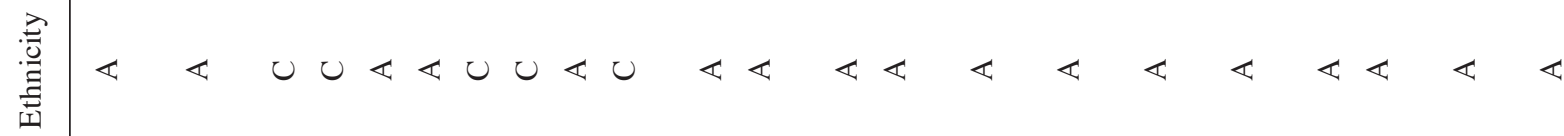

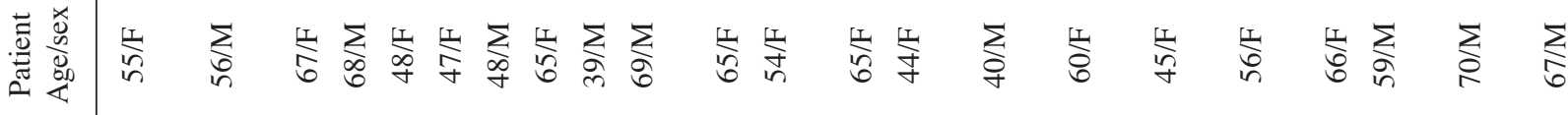




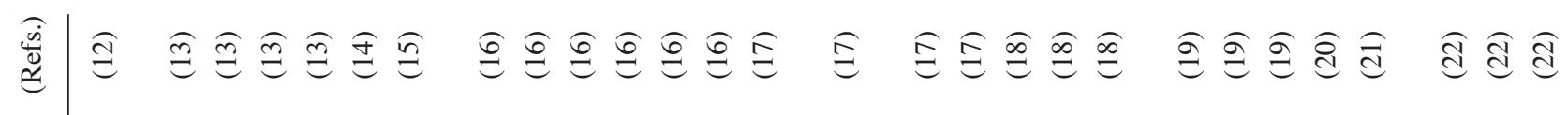

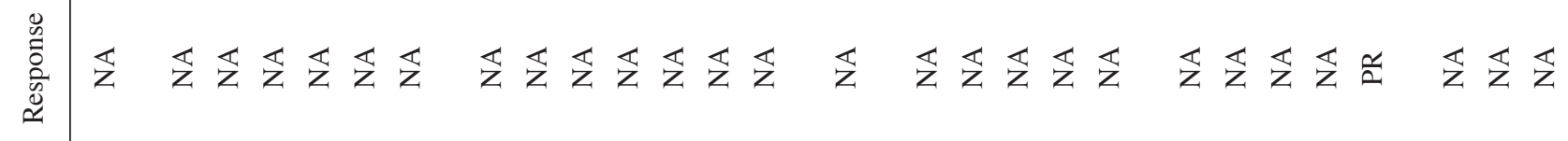

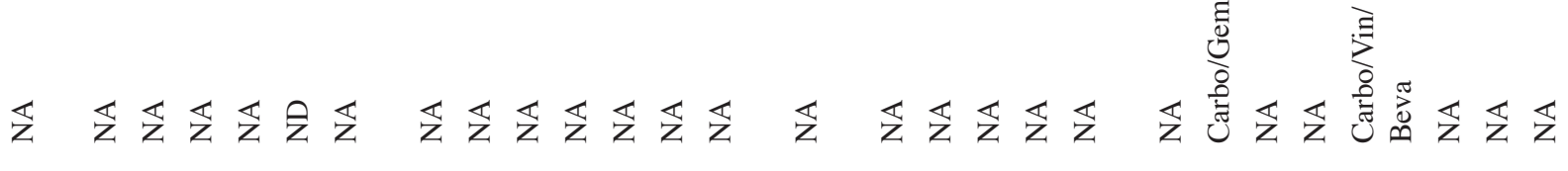

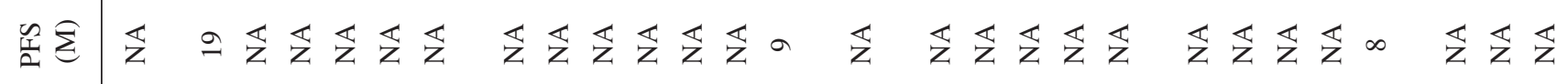

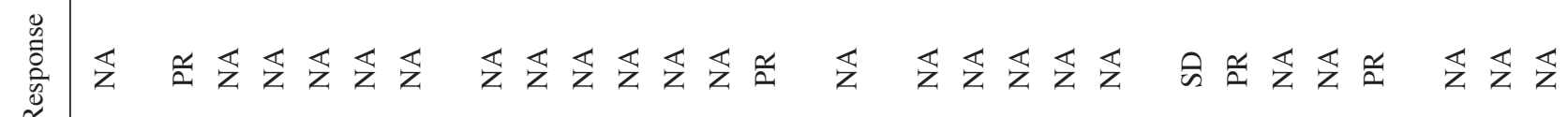

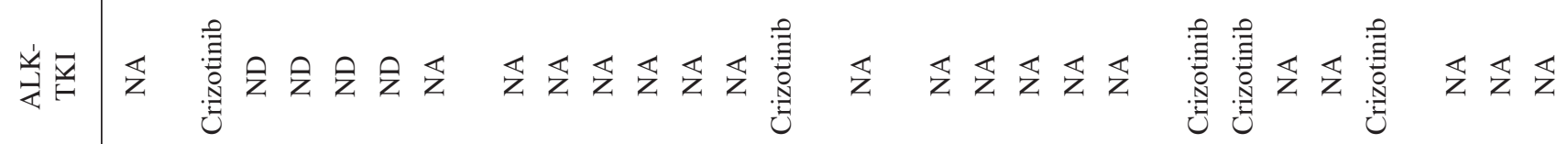

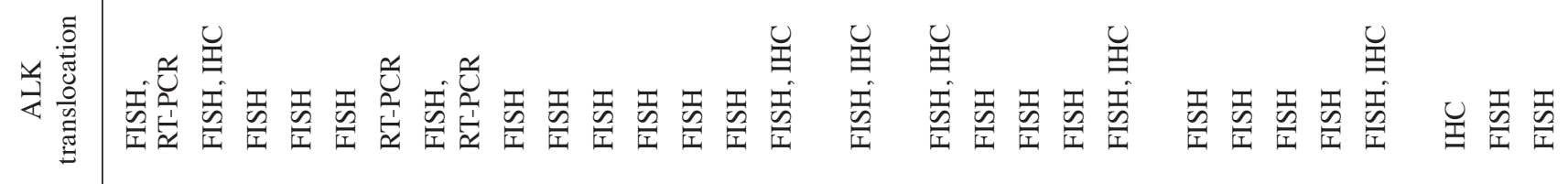

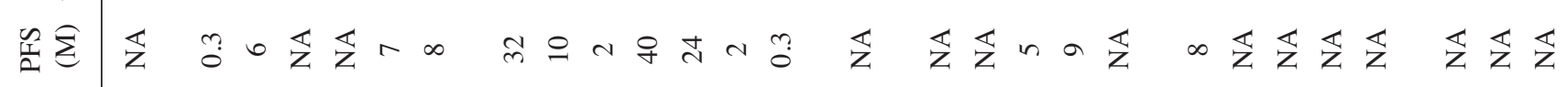

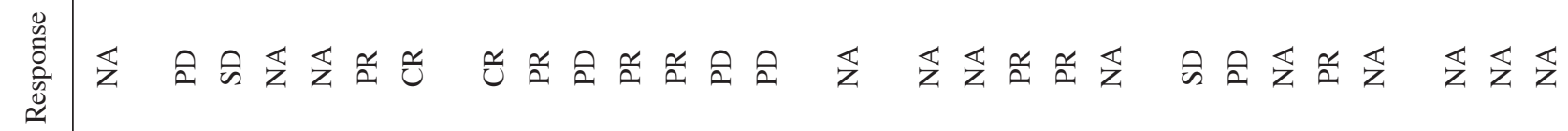

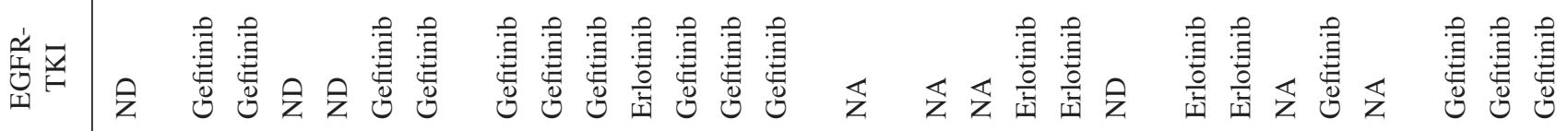

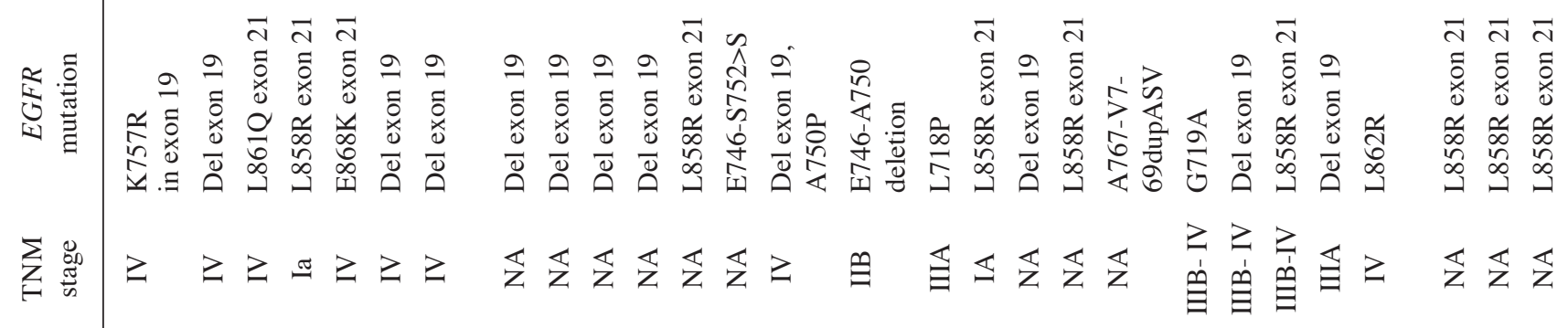

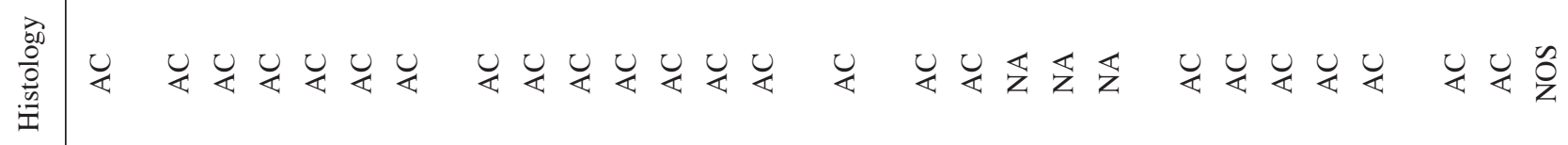

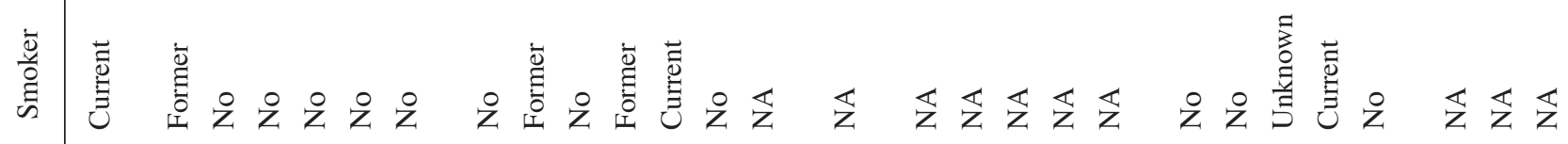

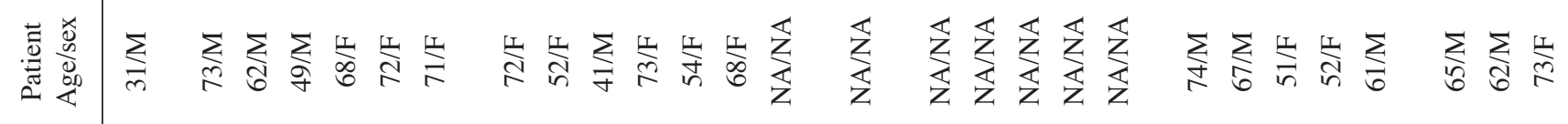

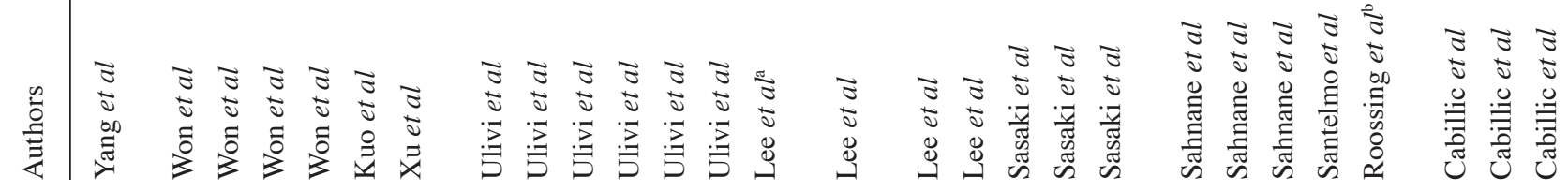




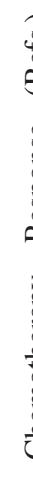

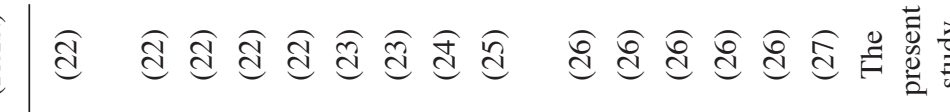

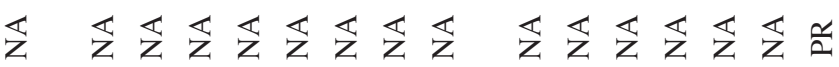

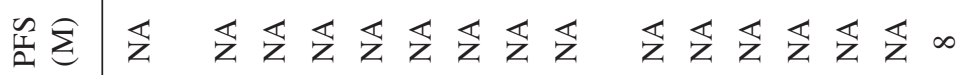

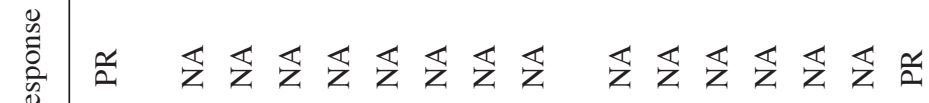

๕ै

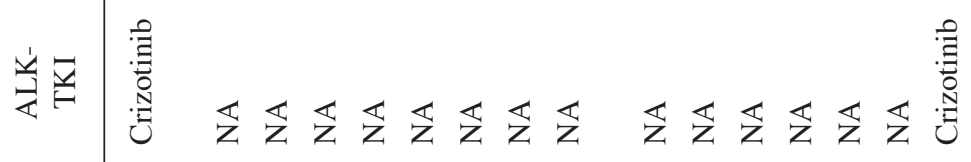

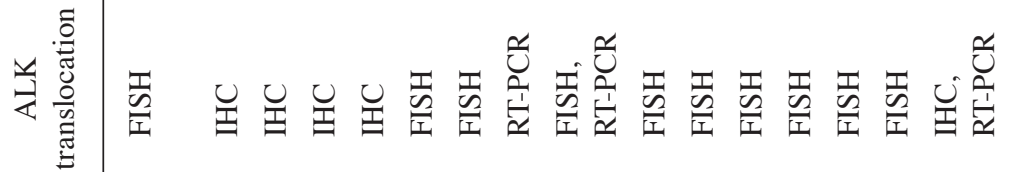

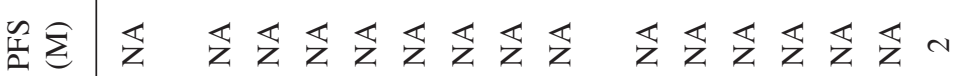

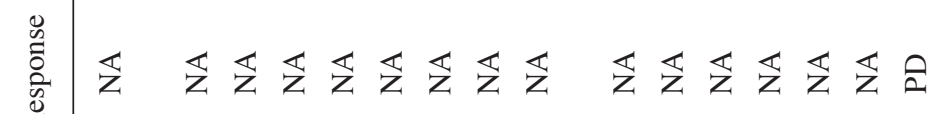

$\approx$

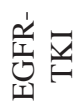

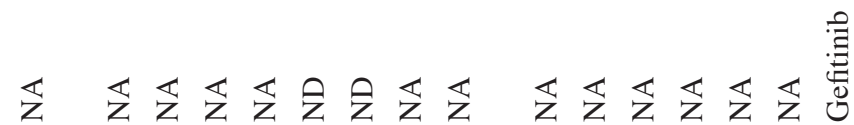

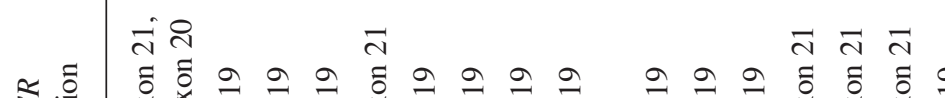

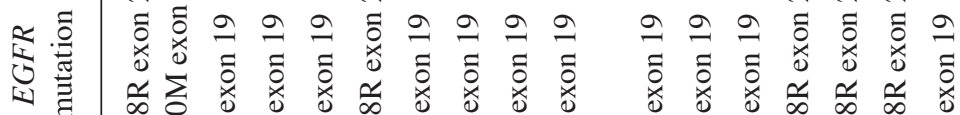

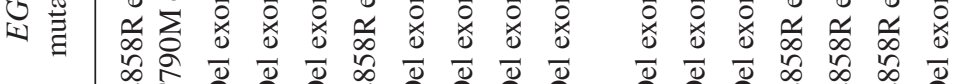

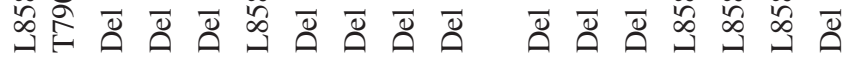

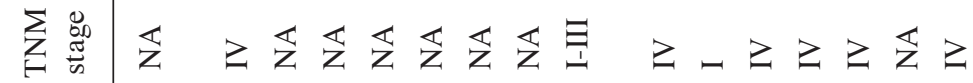

兽

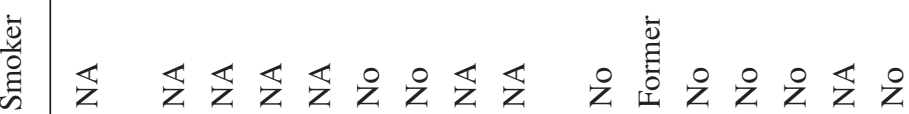

突

善

亭总

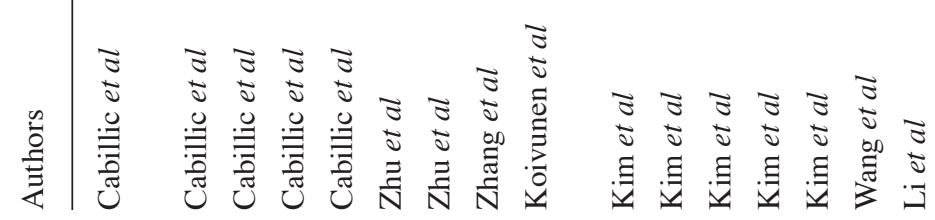

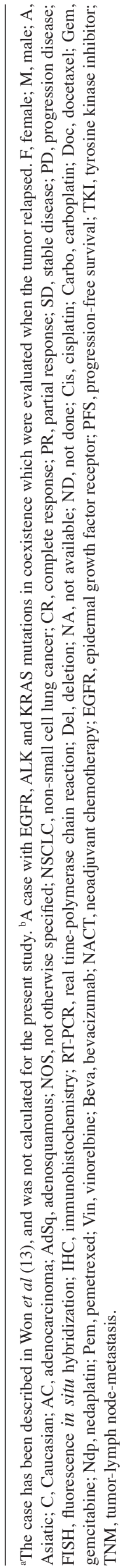




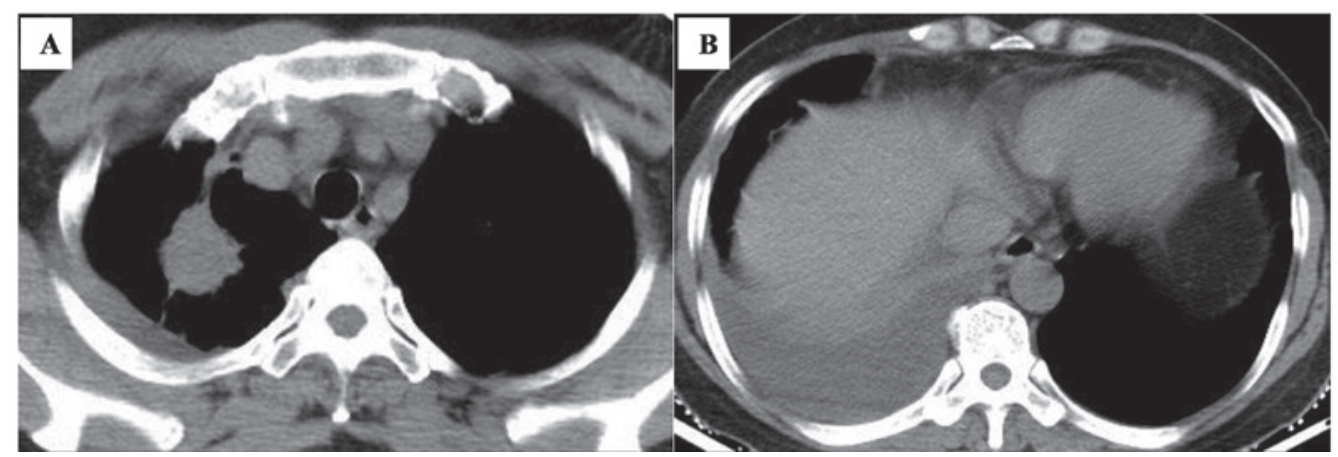

Figure 1. Chest CT images recorded prior to treatment. (A and B) In September 2013, prior to treatment, a chest CT scan revealed a right upper lobe mass and right pleural effusion. CT, computed tomography.

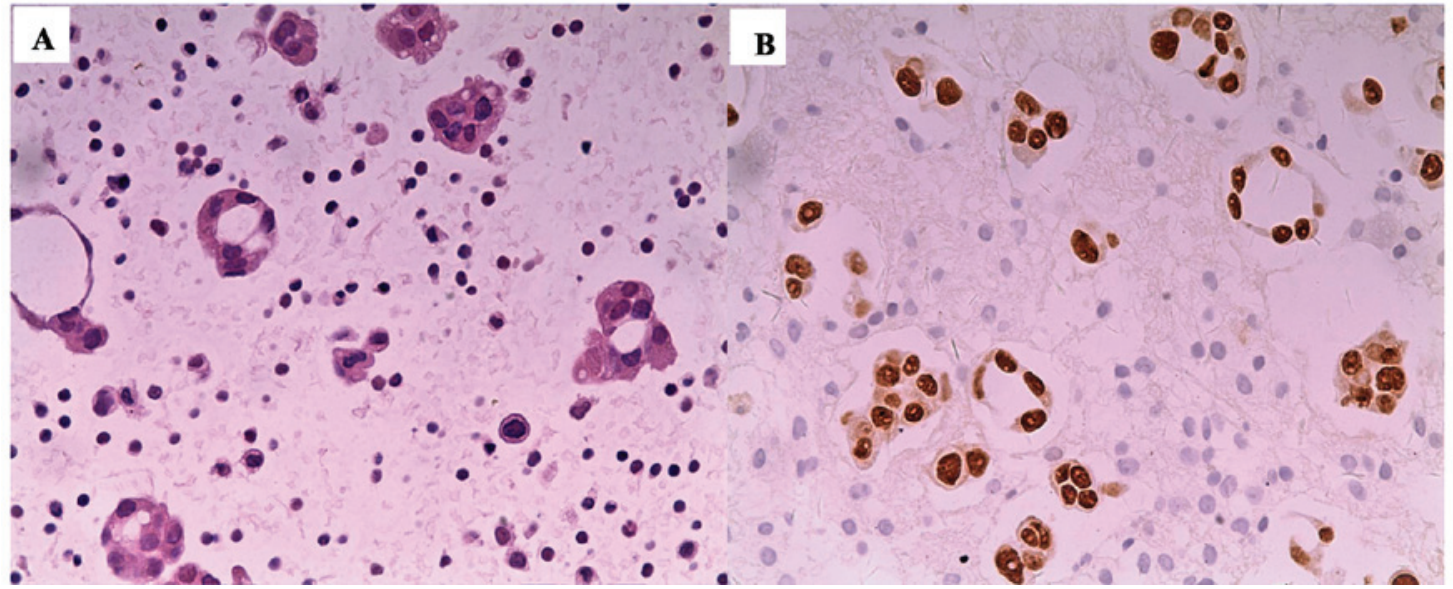

Figure 2. Pathological evaluation of the pleural effusion specimen. The cell-block specimen of pleural effusion revealed adenocarcinoma. (A) Hematoxylin and eosin staining (magnification, x400). (B) Immunoperoxidase staining (magnification, x400), showed positive for thyroid transcription factor-1.

metastatic lung adenocarcinoma (Fig. 2). EGFR mutational analysis was performed on the cell-block material using an amplification refractory mutation system (ARMS) technique (ADx-ARMS kit, Amoy Diagnostics, Xiamen, China). The experimental procedure followed, and data analysis performed, were precisely as described in the manufacturer's protocol. No EGFR mutations were identified in exons 18-21. On the basis of clinical assessment and further imaging studies, the patient was staged as stage IV lung cancer (cT2NOM1). The patient's performance status was 0 according to the Eastern Cooperative Oncology Group (ECOG) scale (28). The patient received a first-line chemotherapy with cisplatin $\left(75 \mathrm{mg} / \mathrm{m}^{2}\right)$ and PEM $\left(500 \mathrm{mg} / \mathrm{m}^{2}\right)$ every three weeks. Following four cycles of the treatment, a repeat CT scan revealed a PR (Fig. 3A and B). The patient was followed with maintenance PEM monotherapy $\left(500 \mathrm{mg} / \mathrm{m}^{2}\right)$ for 12 courses. While continuing to show stable disease (SD), the patient subsequently received radiotherapy for the right upper lobe lung mass, and she was kept on PEM monotherapy with $\mathrm{SD}$, with the exception of small right pleural effusion (Fig. 3C and D).

In March 2015, following 18 months of first-line treatment, the patient again complained of right chest pain and discomfort. A CT scan revealed the recurrence of pleural effusion (Fig. 4A and B), and the effusion specimen was re-evaluated for its pathological and molecular characteristics. In addition to malignant effusion, the cell-block material exhibited $A L K$ gene rearrangement, which was confirmed by an automated immunohistochemistry (IHC) assay (Ventana pre-diluted ALK D5F3 antibody with the Optiview ${ }^{\mathrm{TM}}$ DAB IHC detection kit; Ventana Medical Systems, Inc., Tucson, AZ, USA) (Fig. 5A), and by reverse transcription-quantitative polymerase chain reaction (RT-PCR) assay (Fig. 5B). Notably, an EGFR mutation test performed on the current cell-block material revealed a deletion in exon 19 (delE746-A750; Fig. 5C). Overexpression of EGFR protein was also observed by the IHC assay, using an antibody raised against EGFR (rabbit anti-human EGFR monoclonal antibody; cat. no. RMA-0554, Fuzhou Maixin Biotechnology Development Co. Ltd., Fujian, China) (Fig. 5D).

After the molecular test results has been revealed, the patient started to receive treatment with gefitinib $(250 \mathrm{mg}$, once daily). However, no clinical response was achieved, and a new pleura-based mass (dimensions, $3.0 \times 3.0 \mathrm{~cm}$ ) was identified after two months of gefitinib therapy (Fig. 6A and B). A positron emission tomography (PET)-CT scan demonstrated multiple high metabolic lesions in the right upper lobe, the pleura, right ribs and in the liver under the capsule. In June 2015, the patient began to receive crizotinib $(250 \mathrm{mg}$, twice per day), and she reported a rapid disappearance of discomfort and chest pain. After a further 6 months, the $\mathrm{CT}$ scan revealed a PR (Fig. 6C and D). The patient remained asymptomatic at 
Table II. Characteristics of patients with concomitant EGFR mutation and ALK fusion $(n=65)$.

\begin{tabular}{|c|c|}
\hline Characteristic & No. $(\%)$ \\
\hline Age (median, range) & $60(31-77)$ \\
\hline \multicolumn{2}{|l|}{ Sex } \\
\hline Male & $25(38.5)$ \\
\hline Female & $32(49.2)$ \\
\hline Unknown & $8(12.3)$ \\
\hline \multicolumn{2}{|l|}{ Ethnicity } \\
\hline Asiatic & $37(56.9)$ \\
\hline Caucasian & $27(41.5)$ \\
\hline Unknown & $1(1.5)$ \\
\hline \multicolumn{2}{|l|}{ Smoking status } \\
\hline Non-smokers & $37(56.9)$ \\
\hline Former smokers & $4(6.2)$ \\
\hline Current smokers & $6(9.2)$ \\
\hline Unknown & $18(27.7)$ \\
\hline \multicolumn{2}{|l|}{ Histology } \\
\hline Adenocarcinoma & $59(90.8)$ \\
\hline Adenosquamous carcinoma & $2(3.1)$ \\
\hline Not otherwise specified & $1(1.5)$ \\
\hline Unknown & $3(4.6)$ \\
\hline \multicolumn{2}{|l|}{ TNM stage } \\
\hline I-IIIa & $10(15.4)$ \\
\hline IIIb-IV & $35(53.8)$ \\
\hline Unknown & $20(30.8)$ \\
\hline \multicolumn{2}{|l|}{ EGFR mutation } \\
\hline Del exon 19 & $34(52.3)$ \\
\hline L858R exon 21 & $19(29.2)$ \\
\hline L861Q exon 21 & $3(4.6)$ \\
\hline Others & $9(13.8)$ \\
\hline \multicolumn{2}{|l|}{ ALK translocation } \\
\hline FISH & $33(50.8)$ \\
\hline FISH + IHC & $9(13.8)$ \\
\hline FISH + RT-PCR & $5(7.7)$ \\
\hline FISH + IHC+RT-PCR & $9(13.8)$ \\
\hline $\mathrm{IHC}$ & $5(7.7)$ \\
\hline RT-PCR & $2(3.1)$ \\
\hline IHC + RT-PCR & $2(3.1)$ \\
\hline \multicolumn{2}{|l|}{ EGFR-TKI (n=39) } \\
\hline Gefitinib & $21(53.8)$ \\
\hline Erlotinib & $16(41.6)$ \\
\hline Afatinib & $2(5.1)$ \\
\hline \multicolumn{2}{|l|}{ Response to EGFR-TKI $(n=36)$} \\
\hline $\mathrm{CR} / \mathrm{PR} / \mathrm{SD}$ & $26(72.2)$ \\
\hline PD & $10(27.8)$ \\
\hline
\end{tabular}

PFS of EGFR-TKI, months (median, range) $(n=33) \quad 11.9(0.3-40)$

Response to ALK-TKI (crizotinib; $\mathrm{n}=15$ )

$\mathrm{CR} / \mathrm{PR} / \mathrm{SD}$

$\mathrm{PD}$
Table II. Continued.

\begin{tabular}{lc}
\hline Characteristic & No. $(\%)$ \\
\hline PFS of ALK-TKI, months (median, range) $(\mathrm{n}=12)$ & $10(0.4-25)$ \\
Response to chemotherapy $(\mathrm{n}=12)$ & \\
CR/PR/SD & $9(75.0)$ \\
PD & $3(25.0)$ \\
\hline
\end{tabular}

Del, deletion; EGFR, epidermal growth factor receptor; FISH, fluorescent in situ hybridization; IHC, immunohistochemistry; RT-PCR, real time-polymerase chain reaction; CR, complete response; $\mathrm{PR}$, partial response; $\mathrm{SD}$, stable disease; PD, progression disease; PFS, progression-free survival; TNM, tumor-lymph node-metastasis.

the last follow-up, in April 2016, and at present, she continues to receive crizotinib with the same dose.

This study was approved by the Ethics Committee of The First Affiliated Hospital of Wenzhou Medical University (Wenzhou, China). Written informed consent was obtained from the patient's next of kin.

\section{Discussion}

The prevalence of the coexistence of an $A L K$ gene rearrangement and $E G F R$ mutations may be variable, but it is generally low. Several studies have reported that the frequency ranges from $0-8 \%(24,29)$. Recently, Ulivi et al reported that double mutations were detected in 6 of the 380 (1.6\%) patients with non-small cell lung cancer (NSCLC) (16). Different frequencies may be associated with ethnic differences of the patients and the assay detection sensitivity (13). The optimal treatment, however, has yet to be elucidated, since the responses to EGFR and/or ALK inhibitors have proven to be conflicting $(3,4,9,17,19)$.

Based on a review of the English literature, a total of 65 cases were identified, including the present case, with concomitant EGFR mutations and $A L K$ gene rearrangement. The cases with EGFR mutations detected by sensitive detection methods, such as RT-PCR, targeted next-generation sequencing (NGS), and mutant-enriched NGS, as well as repetitions of the identical cases reported in different journals, were excluded. The patients' clinicopathological characteristics and treatment outcomes are shown in Tables I and II. The patients included 32 women (49.2\%) and 25 men (38.5\%), with $9(13.6 \%)$ patients of unknown sex. The mean age was 60 years old (ranging from 31-77 years). The patients of Asian ethnicity accounted for $56.9 \%$ (37 of 65) of the patients. The patients included $35(56.9 \%)$ never smokers, $4(6.2 \%)$ former smokers and $6(9.2 \%)$ current smokers, with the smoking status unknown in $18(27.7 \%)$ patients. The vast majority of patients (59 of 65 patients; $90.8 \%$ ) were diagnosed with adenocarcinoma, with 35 cases $(53.8 \%)$ being diagnosed at stages IIIb and IV. The EGFR mutations identified were exon 19 deletion in 34 (52.3\%) and exon 21 (L858R) point mutation 19 (29.2\%). ALK gene rearrangement was confirmed using fluorescence in situ hybridization (FISH) assay in 33 (50.8\%) cases, by FISH and IHC in $9(13.8 \%)$ cases, and by FISH and RT-PCR in $5(7.76 \%)$ cases. 


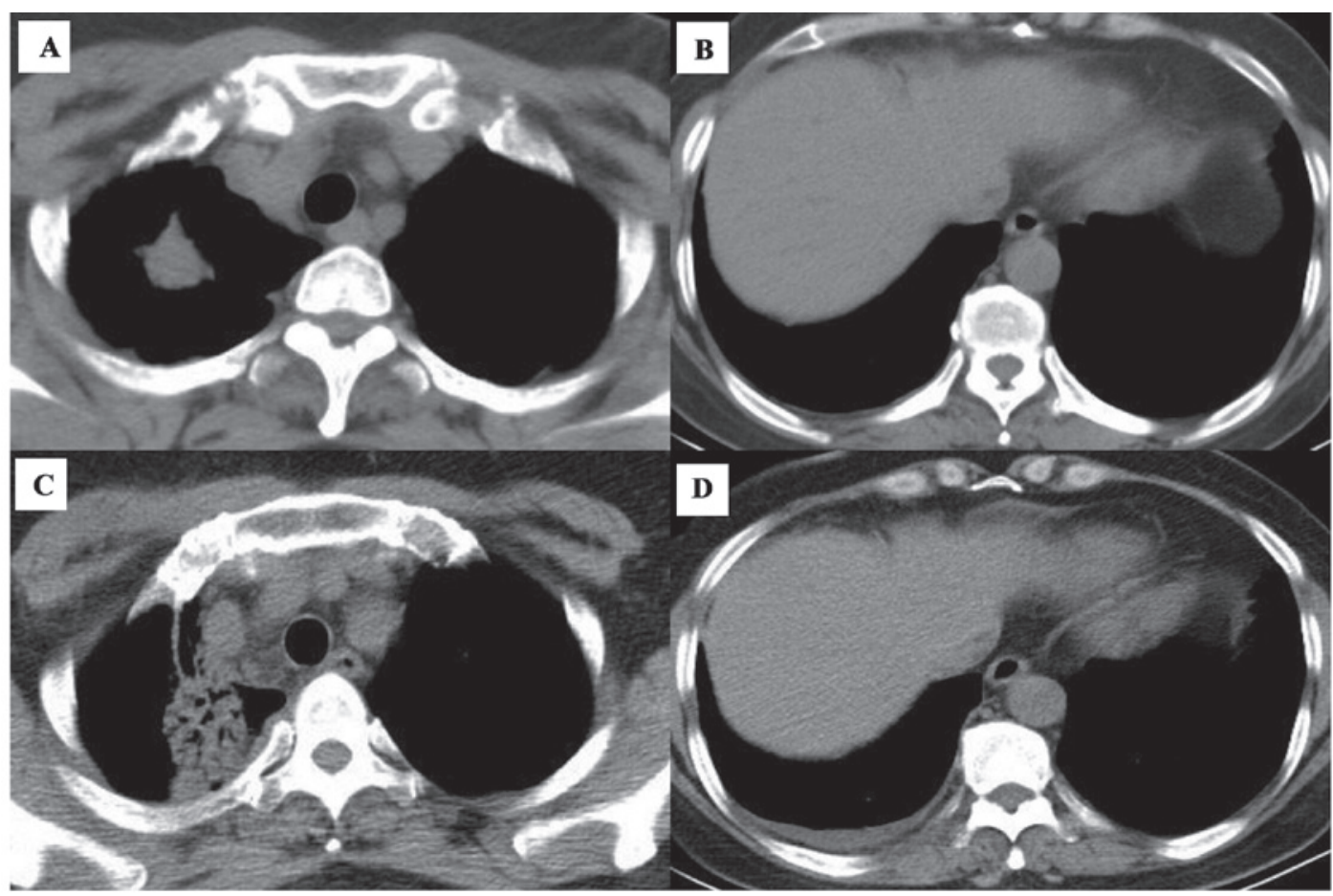

Figure 3. A repeat CT scan recorded after four cycles of PEM combined with cisplatin chemotherapy. (A and B) In December 2013, following four cycles of PEM combined with cisplatin chemotherapy, the response was considered as a partial response. (C and D) In December 2014, following 15 cycles of PEM maintenance therapy and radiotherapy of the right upper lobe lesion, a chest CT revealed stable disease, with the exception of small right pleural effusion. CT, computed tomography; PEM, pemetrexed.

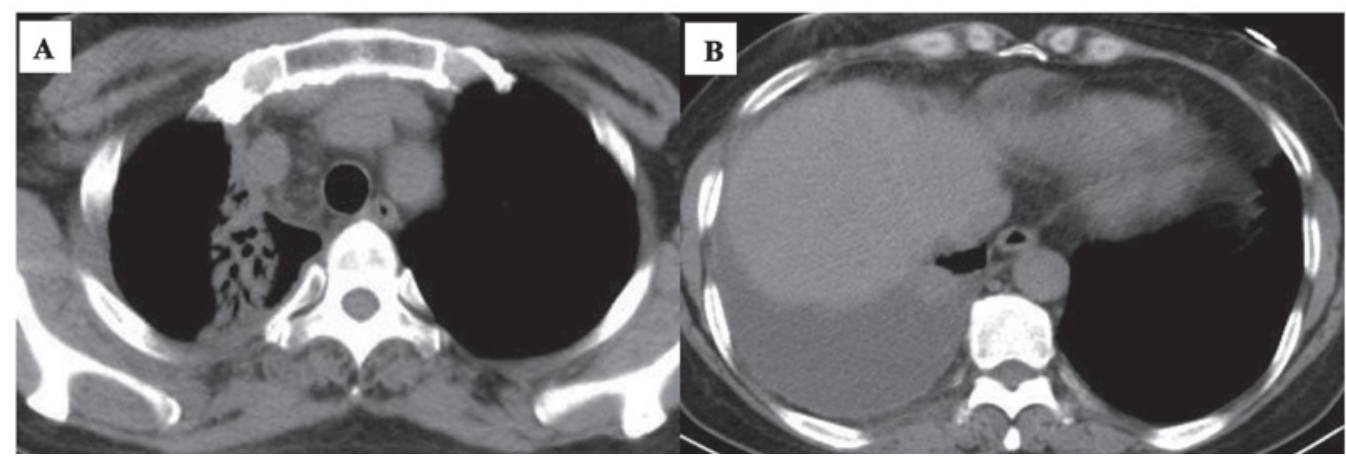

Figure 4. Chest CT images following 18 months of first-line treatment. (A and B) In March 2015, following 18 months of first-line treatment, a chest CT revealed right pleural effusion recurrence. CT, computed tomography.

The efficacy of EGFR-TKI treatments for tumors that were double positive remains inconclusive. From the data presented in Tables I and II, it was noted that 39 (60.0\%) patients had received an EGFR-TKI, 21 (53.8\%) with gefitinib, $16(41.6 \%)$ with erlotinib, and $2(5.1 \%)$ with afatinib. Detailed information about the response to TKIs was provided for 36 patients. Among them, 26 (72.2\%) patients showed a complete response (CR), PR, or SD (disease control rate, DCR), whereas a further 10 (27.8\%) patients experienced progression of disease (PD). The median PFS of EGFR-TKIs was 11.9 months (ranging from 0.3-40 months) in 33 patients, which was similar to the PFS of EGFR-TKI treatment in patients who had the EGFR mutation alone. Zhao et al (6) reported a case of double positive mutations that benefited from a short period treatment of three TKIs. Baldi et al (5) described a case of a double positive NSCLC, in which a good clinical response was observed not only with erlotinib, but also with the ALK inhibitor, crizotinib. However, there are other studies that included double positive patients who did not respond to EGFR-TKIs, but achieved a good response to ALK inhibitors $(12,13,17)$. As illustrated in our case, the patients received EGFR-TKI as a second-line therapy, but exhibited PD, including the occurrence of a new pleura-based mass. Subsequently, crizotinib was administered as a third-line treatment, which revealed a dramatic response. Similar results were reported by Lee et al (17). These authors reported a case of ALK-positive and EGFR-mutant NSCLC patient who did not respond to EGFR-TKI, but achieved a partial response to ALK inhibitors. From the literature review, only 15 (23\%) patients received crizotinib treatment, the majority of whom had crizotinib selected for them as a second-line or third-line therapy. In 12 patients, the DCR was 

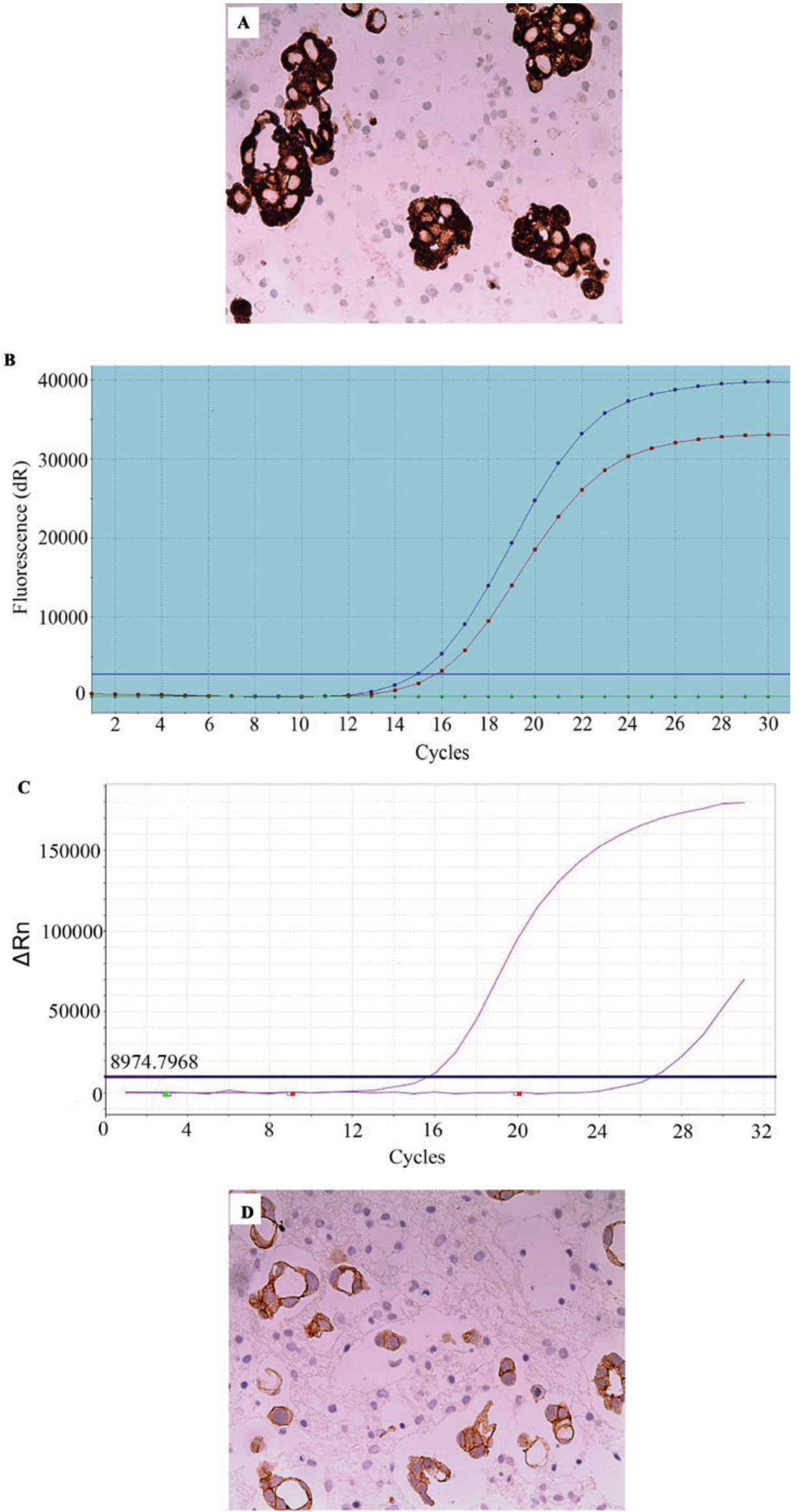

Figure 5. Re-evaluation of the effusion specimen for its pathological and molecular characteristics. (A) Positive ALK staining using a Ventana IHC assay (immunoperoxidase staining; magnification, $\mathrm{x} 400$ ). (B) Positive $A L K$ gene rearrangement using reverse transcription-polymerase chain reaction. (C) Presence of the EGFR mutation was revealed using the amplification refractory mutation system method. (D) Positive EGFR staining by IHC (immunoperoxidase staining, magnification x400). IHC, immunohistochemistry; EGFR, epidermal growth factor receptor. 


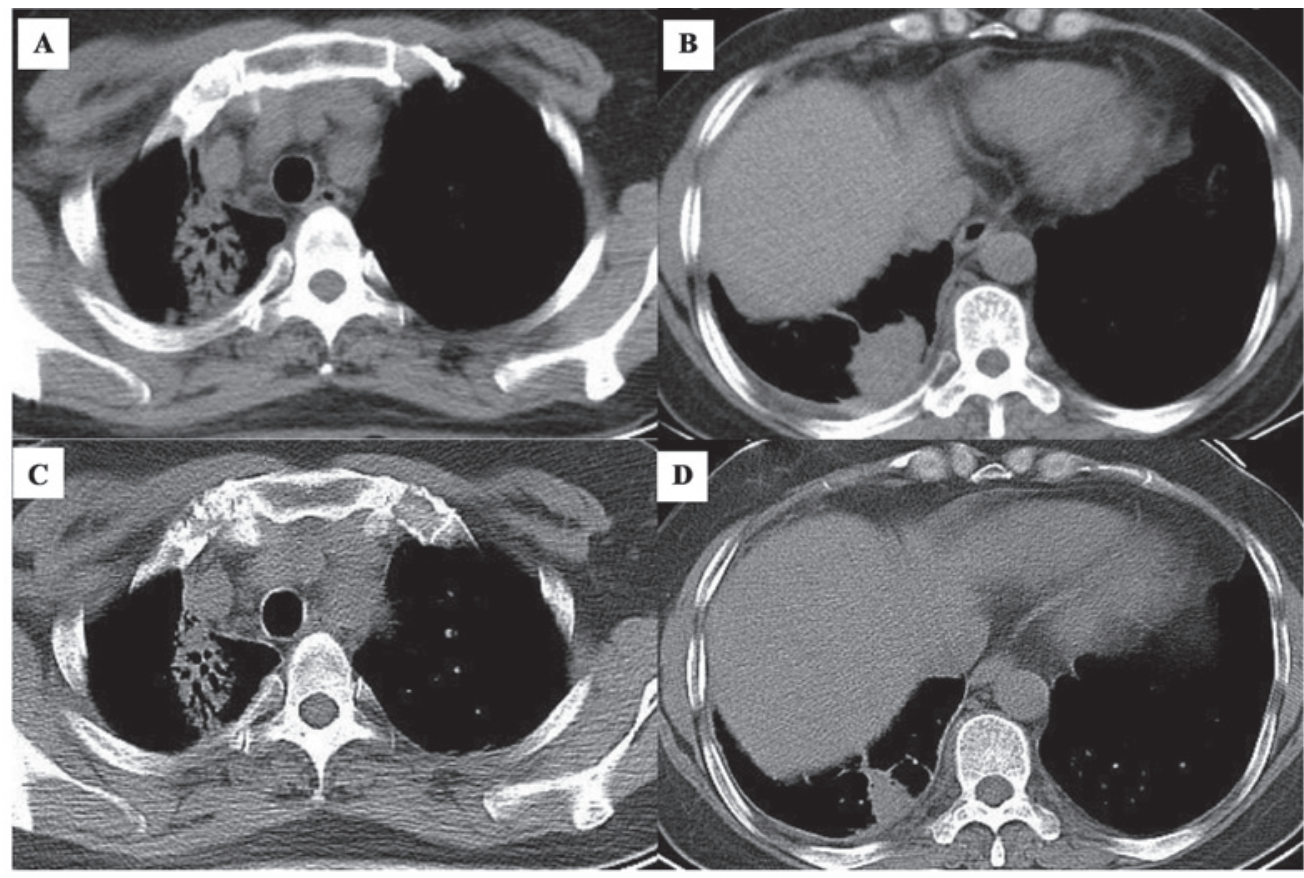

Figure 6. Chest CT scans as the patient was administered treatments with gefitinib and crizotinib. (A and B) In May 2015, after 2 months' treatment with gefitinib, a new mass was observed close to the right pleura. (C and D) Following the crizotinib treatment, the pleural mass was reduced in size, and considered as a partial response.

93.3\% and the median PFS was 10 months (0.4-25 months). Recently, Won et al (13) reported that EGFR-TKIs were not effective in double positive patients, whereas ALK inhibitors were efficient (13). In their study, the majority (7 of 8) patients treated with ALK inhibitors exhibited EGFR mutations by peptide nucleic acid-clamping RT-PCR and/or NGS, but not by Sanger sequencing, which may suggest the possibility of a low burden of EGFR mutants in these patients, although a complete explanation underpinning the lack of response to gefitinib remains unknown. Similarly, Sahnane et al (19) showed that patients with $A L K / E G F R$ mutations might benefit from crizotinib, rather than erlotinib administration. In double positive patients, whichever target drug is more effective may depend on the levels of the two driver gene molecular alterations. From Table II, it was also noted that 12 patients had received chemotherapy, with the DCR being $75 \%$. In the present case study, PEM therapy and crizotinib revealed a good response, and $A L K$ gene rearrangement may have been the primary driven gene mutation. Park et al (30) demonstrated that $A L K$-positive patients had a greater response rate (RR) and longer PFS with PEM-based chemotherapy compared with the patients with EGFR mutations or without an $A L K$ gene rearrangement. The RRs were $26.9,12.8$ and $18.5 \%$, respectively; the PFSs were 7.8, 2.5 and 2.9 months, respectively.

The phenomenon of double positive mutations in NSCLCs may be explained by the heterogeneity of tumor cells: Different genetic alterations may occur in different tumor cells, or multiple oncogenic pathways may be altered in a single clone of tumor cells. Recently, Sahnane et al (19) reported the frequencies of mutant alleles and their gene dosage in double positive patients, suggesting that the EGFR mutation occurs as the first event, and $A L K$ alterations, primarily identified in advanced lung adenocarcinomas, occur late during tumor progression.

With the introduction of precision-targeted therapy in NSCLC and the application of advanced molecular/genetic techniques, more double positive NSCLC patients would be identified. Won et al (13) detected four double positive cases in 1,458 cases of lung cancers for EGFR and ALK alterations by Sanger sequencing and the FISH technique, respectively. However, they identified additional 10 dual positive cases when more sensitive assays were used.

Repeat biopsies are crucial in managing patients with tumor recurrences. As in the present case study, the biopsies offered the opportunity to reassess the mutation profile, which is invaluable for choosing appropriate treatment options. Since the majority of patients with NSCLC are diagnosed through small samples, the tumor heterogeneity or relatively low number of tumor cells may lead to false negative results of EGFR mutations and $A L K$ gene rearrangement. Hence, when obtaining small samples, it is crucial to maximize the number of samples available for molecular studies. Furthermore, in cases that tested positive for EGFR mutations, particularly when the tumors failed to respond to EGFR-TKI treatment, it is important to consider the possibility of double positive mutations, since EGFR mutations and $A L K$ gene rearrangement do coexist in certain tumors.

In conclusion, in the present study, a case of lung adenocarcinoma with concomitant EGFR mutation and $A L K$ gene rearrangement has been reported, which was refractory to gefitinib administration, but exhibited a good response to crizotinib and PEM chemotherapy. A review of the literature demonstrated that the frequencies of coexistence of $A L K$ gene rearrangement and EGFR mutations ranged from $0-8 \%$. Currently, there is no consensus standard therapy for tumors 
with double positive mutations. In cases with double positive mutations, the DCR of EGFR-TKI was reported to be $72.2 \%$, with the PFS being 11.9 months, whereas the DCR of crizotinib was $93.3 \%$, with the PFS being 10 months.

\section{References}

1. Gainor JF, Varghese AM, Ou SH, Kabraji S, Awad MM, Katayama R, Pawlak A, Mino-Kenudson M, Yeap BY, Riely GJ, et al: ALK rearrangements are mutually exclusive with mutations in EGFR or KRAS: An analysis of 1,683 patients with non-small cell lung cancer. Clin Cancer Res 19: 4273-4281, 2013.

2. Miyanaga A, Shimizu K, Noro R, Seike M, Kitamura K, Kosaihira S, Minegishi Y, Shukuya T, Yoshimura A, Kawamoto M, et al: Activity of EGFR-tyrosine kinase and ALK inhibitors for EML4-ALK-rearranged non-small-cell lung cancer harbored coexisting EGFR mutation. BMC Cancer 13: 262, 2013.

3. Chen X, Zhang J, Hu Q, Li X and Zhou C: A case of lung adenocarcinoma harboring exon 19 EGFR deletion and EML4-ALK fusion gene. Lung Cancer 81: 308-310, 2013.

4. Chiari R, Duranti S, Ludovini V, Bellezza G, Pireddu A, Minotti V, Bennati $\mathrm{C}$ and Crinò L: Long-term response to gefitinib and crizotinib in lung adenocarcinoma harboring both epidermal growth factor receptor mutation and EML4-ALK fusion gene. J Clin Oncol 32: e30-e32, 2014.

5. Baldi L, Mengoli MC, Bisagni A, Banzi MC, Boni C and Rossi G: Concomitant EGFR mutation and ALK rearrangement in lung adenocarcinoma is more frequent than expected: Report of a case and review of the literature with demonstration of genes alteration into the same tumor cells. Lung Cancer 86: 291-295, 2014

6. Zhao N, Zheng SY, Yang JJ, Zhang XC, Xie Z, Xie B, Su J, Chen ZH, Chen SL, Zhang N, et al: Lung adenocarcinoma harboring concomitant EGFR mutation and EML4-ALK fusion that benefits from three kinds of tyrosine kinase inhibitors: A case report and literature review. Clin Lung Cancer 16: e5-e9, 2015.

7. Zhou J, Zheng J, Zhao J, Sheng Y, Ding W and Zhou J: Poor response to gefitinib in lung adenocarcinoma with concomitant epidermal growth factor receptor mutation and anaplastic lymphoma kinase rearrangement. Thorac Cancer 6: 216-219, 2015.

8. Tiseo M, Gelsomino F, Boggiani D, Bortesi B, Bartolotti M, Bozzetti C, Sammarelli G, Thai E and Ardizzoni A: EGFR and EML4-ALK gene mutations in NSCLC: A case report of erlotinib-resistant patient with both concomitant mutations Lung Cancer 71: 241-243, 2011.

9. Popat S, Vieira de Araújo A, Min T, Swansbury J, Dainton M, Wotherspoon A, Lim E, Nicholson AG and O'Brien ME: Lung adenocarcinoma with concurrent exon 19 EGFR mutation and ALK rearrangement responding to erlotinib. J Thorac Oncol 6: 1962-1963, 2011.

10. Tanaka H, Hayashi A, Morimoto T, Taima K, Tanaka Y, Shimada M, Kurose A, Takanashi S and Okumura K: A case of lung adenocarcinoma harboring EGFR mutation and EML4-ALK fusion gene. BMC Cancer 12: 558, 2012.

11. Jurgens J, Engel-Riedel W, Prickartz A, Ludwig C, Schildgen O, Tillmann RL, Stoelben E, Brockmann M and Schildgen V: Combined point mutation in KRAS or EGFR genes and EML4-ALK translocation in lung cancer patients. Future Oncol 10: 529-532, 2014.

12. Yang JJ, Zhang XC, Su J, Xu CR, Zhou Q, Tian HX, Xie Z, Chen HJ, Huang YS, Jiang BY, et al: Lung cancers with concomitant EGFR mutations and ALK rearrangements: Diverse responses to EGFR-TKI and crizotinib in relation to diverse receptors phosphorylation. Clin Cancer Res 20: 1383-1392, 2014

13. Won JK, Keam B, Koh J, Cho HJ, Jeon YK, Kim TM, Lee SH, Lee DS, Kim DW and Chung DH: Concomitant ALK translocation and EGFR mutation in lung cancer: A comparison of direct sequencing and sensitive assays and the impact on responsiveness to tyrosine kinase inhibitor. Ann Oncol 26: 348-354, 2015.

14. Kuo YW, Wu SG, Ho CC and Shih JY: Good response to gefitinib in lung adenocarcinoma harboring coexisting EML4-ALK fusion gene and EGFR mutation. J Thorac Oncol 5: 2039-2040, 2010.

15. Xu CW, Cai XY, Shao Y, Li Y, Shi MW, Zhang LY, Wang L, Zhang YP, Wang LP and Tian YW: A case of lung adenocarcinoma with a concurrent EGFR mutation and ALK rearrangement: A case report and literature review. Mol Med Rep 12: 4370-4375, 2015.
16. Ulivi P, Chiadini E, Dazzi C, Dubini A, Costantini M, Medri L, Puccetti M, Capelli L, Calistri D, Verlicchi A, et al: Nonsquamous, non-small-cell lung cancer patients who carry a double mutation of EGFR, EML4-ALK or KRAS: Frequency, clinical-pathological characteristics, and response to therapy. Clin Lung Cancer 17: 384-390, 2016.

17. Lee JK, Kim TM, Koh Y, Lee SH, Kim DW, Jeon YK, Chung DH, Yang SC, Kim YT, Kim YW, et al: Differential sensitivities to tyrosine kinase inhibitors in NSCLC harboring EGFR mutation and ALK translocation. Lung Cancer 77: 460-463, 2012.

18. Sasaki T, Koivunen J, Ogino A, Yanagita M, Nikiforow S, Zheng W, Lathan C, Marcoux JP, Du J, Okuda K, et al: A novel ALK secondary mutation and EGFR signaling cause resistance to ALK kinase inhibitors. Cancer Res 71: 6051-6060, 2011.

19. Sahnane N, Frattini M, Bernasconi B, Zappa F, Schiavone G, Wannesson L, Antonelli P, Balzarini P, Sessa F, Mazzucchelli L, et al: EGFR and KRAS mutations in ALK-positive lung adenocarcinomas: Biological and clinical effect. Clin Lung Cancer 17: 56-61, 2016.

20. Santelmo C, Ravaioli A, Barzotti E, Papi M, Poggi B, Drudi F, Mangianti M, Salvi M and Crinò L: Coexistence of EGFR mutation and ALK translocation in NSCLC: Literature review and case report of response to gefitinib. Lung Cancer 81: 294-296, 2013.

21. Rossing HH, Grauslund M, Urbanska EM, Melchior LC, Rask CK, Costa JC, Skov BG, Sørensen JB and Santoni-Rugiu E: Concomitant occurrence of EGFR (epidermal growth factor receptor) and KRAS (V-Ki-ras2 Kirsten rat sarcoma viral oncogene homolog) mutations in an ALK (anaplastic lymphoma kinase)-positive lung adenocarcinoma patient with acquired resistance to crizotinib: A case report. BMC Res Notes 6: 489 , 2013.

22. Cabillic F, Gros A, Dugay F, Begueret H, Mesturoux L, Chiforeanu DC, Dufrenot L, Jauffret V, Dachary D, Corre R, et al: Parallel FISH and immunohistochemical studies of ALK status in 3244 non-small-cell lung cancers reveal major discordances. J Thorac Oncol 9: 295-306, 2014.

23. Zhu J, Cai L, Yang H, Wen Y, Wang J, Rong T, Shao J and Zhang L: Echinoderm microtubule-associated protein-like 4-anaplastic lymphoma kinase rearrangement and epidermal growth factor receptor mutation coexisting in Chinese patients with lung adenocarcinoma. Thorac Cancer 5: 411-416, 2014.

24. Zhang X, Zhang S, Yang X, Yang J, Zhou Q, Yin L, An S, Lin J, Chen S, Xie Z, et al: Fusion of EML4 and ALK is associated with development of lung adenocarcinomas lacking EGFR and KRAS mutations and is correlated with ALK expression. Mol Cancer 9: 188, 2010.

25. Koivunen JP, Mermel C, Zejnullahu K, Murphy C, Lifshits E, Holmes AJ, Choi HG, Kim J, Chiang D, Thomas R, et al: EML4-ALK fusion gene and efficacy of an ALK kinase inhibitor in lung cancer. Clin Cancer Res 14: 4275-4283, 2008.

26. Kim TJ, Park CK, Yeo CD, Park K, Rhee CK, Kim J, Kim SJ, Lee SH, Lee KY and Yoon HK: Simultaneous diagnostic platform of genotyping EGFR, KRAS, and ALK in 510 Korean patients with non-small-cell lung cancer highlights significantly higher ALK rearrangement rate in advanced stage. J Surg Oncol 110: 245-251, 2014.

27. Wang J, Dong Y, Cai Y, Zhou L, Wu S, Liu G, Su D, Li X, Qin N, Nong J, et al: Clinicopathologic characteristics of ALK rearrangements in primary lung adenocarcinoma with identified EGFR and KRAS status. J Cancer Res Clin Oncol 140: 453-460, 2014.

28. Oken MM, Creech RH, Tormey DC, Horton J, Davis TE, McFadden ET and Carbone PP: Toxicity and response criteria of the eastern cooperative oncology group. Am J Clin Oncol 5: 649-655, 1982.

29. Shaw AT, Yeap BY, Mino-Kenudson M, Digumarthy SR, Costa DB, Heist RS, Solomon B, Stubbs H, Admane S, McDermott U, et al: Clinical features and outcome of patients with non-small-cell lung cancer who harbor EML4-ALK. J Clin Oncol 27: 4247-4253, 2009.

30. Park S, Park TS, Choi CM, Lee DH, Kim SW, Lee JS, Kim WS, Song JS and Lee JC: Survival benefit of pemetrexed in lung adenocarcinoma patients with anaplastic lymphoma kinase gene rearrangements. Clin Lung Cancer 16: e83-e89, 2015. 